\title{
Frontotemporal lobar degeneration with MAPT mutation in an Italian-Polish family. A case report
}

\author{
Teresa Wierzba-Bobrowicz ${ }^{1}$, Eliza Lewandowska ${ }^{1}$, Jacek Zaremba ${ }^{2}$, Mariusz Berdyński ${ }^{3}$, Cezary Żekanowski ${ }^{3}$, \\ Tomasz Stępień ${ }^{1}$, Paulina Felczak ${ }^{1}$, Sylwia Tarka ${ }^{4}$ \\ ${ }^{1}$ Department of Neuropathology, Institute of Psychiatry and Neurology, Warsaw, ${ }^{2}$ Department of Genetics, Institute of Psychiatry \\ and Neurology, Warsaw, ${ }^{3}$ Department of Neurodegenerative Disorders and Neurogenetic Unit, Mossakowski Medical Research \\ Institute, Polish Academy of Sciences, Warsaw, ${ }^{4}$ Department of Forensic Medicine, Warsaw Medical University, Poland
}

\begin{abstract}
Frontotemporal lobar degeneration (FTLD) with mutations in the MAPT (microtubule-associated protein tau) gene (FTLD with MAPT mutation) is a neurodegenerative disease with various clinical phenotypes. We present an ItalianPolish family with a IVS10+3G>A mutation in the MAPT gene, linked with haplotype H1s in a male proband (Fig. 2, II.2, H1s/H1b diplotype) and his sister (Fig. 2, II.1, the H1s/H1j diplotype). This report presents clinical, neuropathological and genetic testing of the proband and his affected sister, two members of an Italian-Polish family consisting of 25 family members. Their clinical history includes dementia as well as movement and cardiovascular disorders. Magnetic resonance imaging showed frontal and temporal cerebral atrophy. Neuropathological studies of the brain samples showed loss of neurons, gliosis, and the occurrence of neurofibrillary tangles, numerous neuropil threads, coiled bodies and abundant deposits of tau protein, including 3- and 4-repeated isoforms in neurons and glial cells. Only in the male proband brain, there were Pick body-like deposits in granule neurons of the hippocampus. Pathology of vascular walls was found in both cases. Ultrastructurally, the male proband showed clusters of collagen fibers mainly in a pericyte position. Beside the typical neurofibrillary pathology, aggregated gliofilaments and lipofuscin deposits in astroglia are described. Our report suggests that FTLD with IVS10+3G>A MAPT mutation causes damage mainly to the central nervous system and induces neuropathological changes, depending on the haplotypes of MAPT. In the clinical course of this disease, damage of the cardiovascular system may also be observed.
\end{abstract}

Key words: FTLD, MAPT, H1 haplotypes, diplotypes H1s/H1j and H1s/H1b, tau isoforms.

\section{Introduction}

Frontotemporal lobar degeneration (FTLD) represents a large heterogeneous group of familial and sporadic diseases, in which the neurodegenerative process involves mainly the frontal and temporal lobes (Fig. 1) [3]. The group of these diseases constitutes about $20 \%$ of presenile dementia cases [18]. Hereditary forms of FTLD are associated with mutations of multiple genes, including MAPT (microtubule-associated protein tau gene), PGRN (progranulin gene), VCP (valosin-containing protein gene), $C H M P_{2} B$ (charged multivesicular body protein ${ }_{2} B$ gene), 


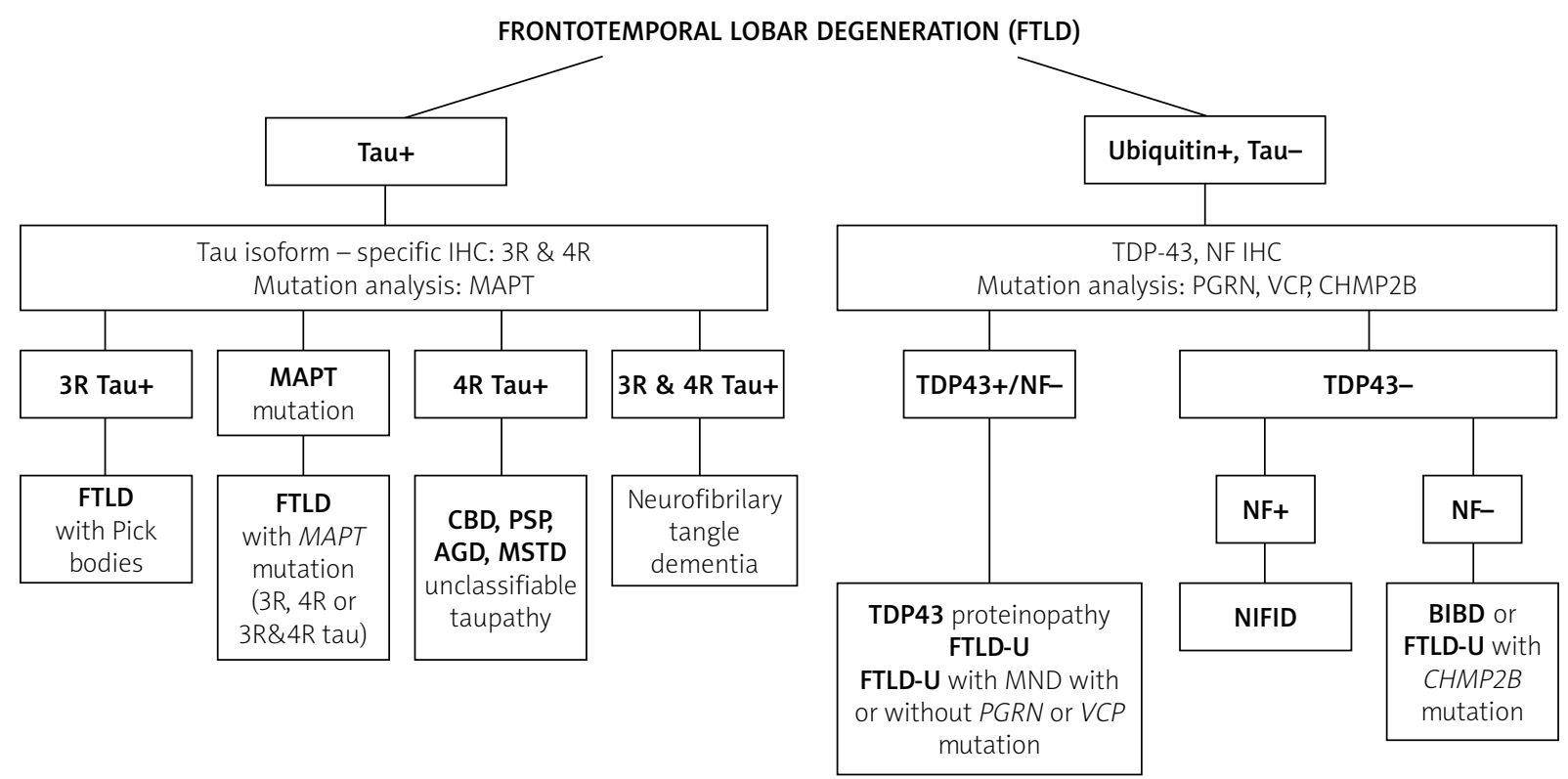

Fig. 1. Neuropathology algorithm flow chart for the diagnosis of frontotemporal lobar degeneration (FTLD) by Cairns et al. (Acta Neuropathol 2007; 114: 5-22). AGD - argyrophilic grain disease, BIBD - basophilic inclusion body disease, CBD - corticobasal degeneration, CHMP2B - charged multivesicular body protein 2B gene, FTLD-U - FTLD with ubiquitin-positive, tau-negative inclusions, IHC - immunohistochemistry, MAPT - microtubule-associated protein tau gene, MSTD - sporadic multiple system tauopathy with dementia, NIFID - neuronal intermediate filament inclusion disease, NF - neurofilament, PGRN - progranulin gene, PSP - progressive supranuclear palsy, TDP-43 - TAR DNA-binding protein 43, Tau - tau protein, VCP valosin-containing protein gene.

TDP-43 (TAR DNA-binding protein 43) and other mutations $[4,17]$. MAPT mutations are identified in up to $20 \%$ of familial FTLD $[9,20]$. The MAPT gene codes the microtubule-associated protein tau, which is involved in microtubule assembly and stabilization, neuronal polarity, and axonal transport in the brain $[7,20]$. The tau protein is mainly synthesized in the peripheral and central nervous system (central nervous system [CNS], neurons and neuroglia), but it is also expressed in other tissues (heart, skeletal muscle, lung, kidney and others) $[1,8,16]$. The MAPT gene locus on chromosome 17 q21 has two major haplotypes, $\mathrm{H} 1$ and $\mathrm{H} 2$. MAPT consists of 16 exons and encodes 6 human brain isoforms of tau protein with 3 or 4 repeat domains ( $3 R$ and $4 R$ ) $[2,5,15]$. Tau protein inclusions in different tauopathies have specific morphology and distribution. In the nervous system of FTLD patients carrying the MAPT mutation, inclusions of both $3 R$ tau and $4 R$ isoforms of tau protein are found. The $3 R$ isoform of tau protein inclusions are observed in FTLD with Pick bodies, while the $4 R$ isoform of tau protein occurs, inter alia, in such diseases as corticobasal degeneration, progressive supranuclear palsy and argyrophilic grain disease [6]. More than 40 mutations have been identified in the MAPT gene in individuals from more than 100 families with FTLD $[6,12,27]$. Depending on the mutation in the MAPT gene, we can observe different neuropathologic and clinical symptoms. There are also differences between family members and families suffering from FTLD with the same MAPT mutations. The main hallmarks of this disease are neurofibrillary pathology, neuronal inclusions, tau-positive neuroglial inclusions, both in astrocytic and oligodendrocytic cells and also the coiled bodies $[5,11,13,26]$. In this study, we investigated immunohistochemically, using antibodies against 3R- and 4R-tau isoforms, genetic and ultrastructural features of two members of Italian-Polish familial FTLD with dementia and movement disorders.

\section{Material and methods \\ The reported cases}

The pedigree consists of 25 Italian-Polish family members in four generations. The first tested pro- 


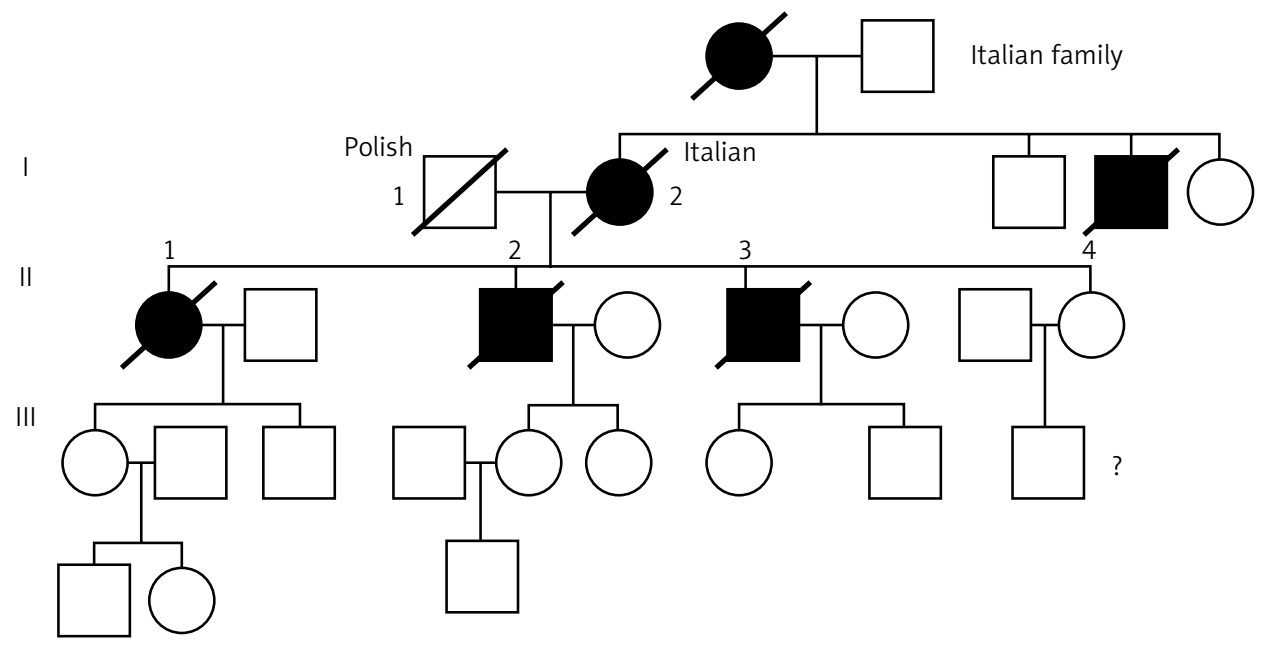

Fig. 2. Pedigree of the frontotemporal lobar degeneration with MAPT mutation of the Italian- Polish family. I.2 Italian grandmother, her mother and brother also with dementia and movement disorders in the family medical history. I.1 grandfather (Pole) without symptoms. II.2 the first tested male proband with mutation in MAPT gene, II.1 his sister with mutation in MAPT gene, II.3 brother with dementia and movement disorders in the family medical history, III. family members were not examined, currently without clinical symptoms.

band, a 58-year-old man (Fig. 2, II.2), died one year after the onset of the first dementia symptoms. At the age of 49 , he had a cardiac pacemaker implanted. The patient complained of muscle weakness. At the end of his life, bulbar syndrome occurred. The diagnosis of Alzheimer's disease was suspected. The proband's sister (Fig. 2, II.1) died at the age of 68 . She presented with behavioral abnormalities from the age of 59. Primarily, the loss of awareness, memory, interest and empathy was noted. Gradually social withdrawal and logopenic aphasia progressed. At the age of 61 she was afflicted by brain hemorrhagic stroke. At the end of her life, pyramidal and Parkinsonian syndromes were reported. Magnetic resonance imaging (MRI) showed cerebral atrophy in frontal and temporal lobes (Fig. 3).

\section{Methods}

Brain examinations were performed. Samples were taken from the brain structures of the affected male proband (II.2) and his sister (II.1). They were fixed in $10 \%$ buffered formalin and paraffin embedded. The specimens were stained with hematoxylin-eosin, Bielshowsky, Yamamoto, and Gallyas methods. Immunohistochemical studies were performed with antibodies to glial fibrillary acidic protein (GFAP, DAKO 1 : 70), anti-tau (DAKO 1 : 100), anti-Tau, 3R-re-

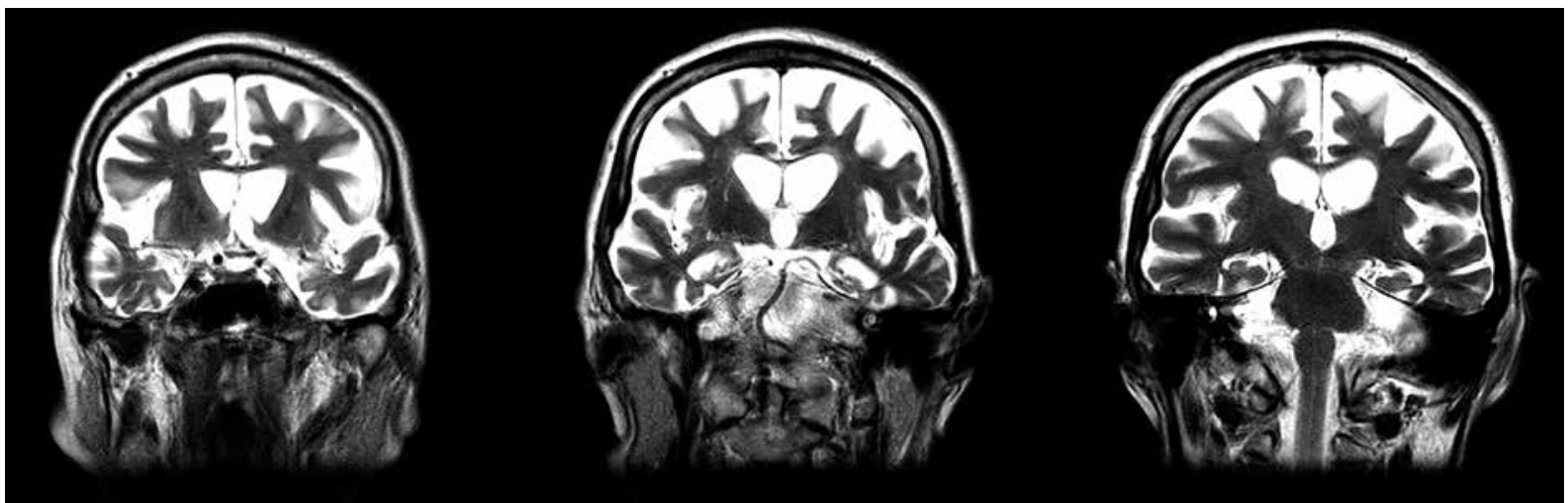

Fig. 3. Magnetic resonance imaging scans of frontotemporal lobar degeneration with MAPT mutation. Case II.1 sister (6 years of disease). Atrophy of frontal and temporal lobes. 
peated isoform RD3 (Millipore, $1: 1000$ ), anti-tau-4R repeated isoform RD4 (Millipore, $1: 1000$ ), ubiquitin (DAKO, $1: 35$ ), $\beta$-amyloid (DAKO, $1: 70$ ) and $\alpha$-synuclein (Leica, $1: 20$ ). For electron microscope evaluation small fragments of brains were taken from formalin or paraffin blocks. After deparaffinizing and/ or washing in water, the material was fixed in $2.5 \%$ glutaraldehyde and postfixed in $2 \% \mathrm{OsO}$, then routinely processed to Spurr resin. Ultrathin sections were stained with uranyl acetate and lead citrate and examined in an electron microscope (Opton DPS 109). Blood samples for DNA analysis were protected. Genomic DNA was isolated from peripheral blood leukocytes using standard methods. The male proband was screened for mutations in: PSEN1, APP, $P G R N, M A P T$, and C9ORF72. The presence of the mutation also was confirmed in the proband's sister. The absence of the mutation IVS10+3G $>$ A MAPT was confirmed in the control group of 150 elderly, neurologically healthy subjects from the Polish population. Haplotype associated with the mutation was identified by the presence or absence of 238 bp deletion in intron 9 and by genotyping five SNPs (rs1467967, rs242557, rs3785883, rs2471738 and rs7521) [22]. The mutation-associated haplotype was determined based on the comparison of diplotypes identified in the male proband and his sister.

\section{Results}

In both cases, the gross examination of the brains showed moderate symmetrical cortical atrophy in the frontal and temporal lobes. There was mild atrophy of the anterior part of the caudate nucleus, while other subcortical structures were normal. The lateral ventricles were intensively dilated. The substantia nigra of the mesencephalon and locus coeruleus of the pons were moderately depigmented. The cerebellum seemed to be normal. Routine histology of the light microscopy examination showed neocortical neuronal loss, mostly in the frontal and temporal lobes in layers II and III and also in the substantia nigra. This change was accompanied by moderate spongiosis and astrogliosis. Sections stained with either the Bielschowski, Yammamoto or Gallyas silver technique showed neurofibrillary tangles (NFTs) and neuropil threads (NTs) (Fig. 4A,B). Silver-stained fibrillary inclusions were found in Purkinje cells and neurons of the substantia nigra and also in the locus coeruleus (Fig. 4C-E). Numerous coiled bodies were observed in the white matter in frontal and temporal lobes (Fig. 4F,G). Ballooned neurons were detected in the pons and in the cerebral and cerebellar cortices (Fig. 4H). Tau-immunoreactive methods detected many more NFTs, coiled bodies and NTs than silver methods. Tau-immunoreactive deposits were abundant in the frontal and temporal cortex but also in the brainstem. They were visible in the form of granular deposits, tau-positive abundant neurites, neuropil threads, coiled bodies, Pick bodies, ballooned neurons and grain-like deposits (Fig. 5 and 6). Tau-3 repeated isoform positive Pick bodies in the granule neurons of the dentate gyrus of the hippocampus occurred only in the male proband (Fig. 5C), whereas intracytoplasmic deposits of tau-4 repeated isoform were observed in both cases (Fig. 5D and 6E). In the frontal cortex of the sister, tau-positive Pick bodies-like deposits were visible (Fig. 6F). A GFAP-positive tufted and monstrous astrocytes were observed mainly in the sister (Fig. 2, II.1) (Fig. 6H and 6J). Pathology of vascular walls was visible in both cases (Fig. $5 \mathrm{~J}$ and $6 \mathrm{~J}$ ). Ultrastructural analysis of fibrillary inclusions showed tightly aggregated filaments of neurofibrillary tangles in the cytoplasm of nerve cells (Fig. 7). Astrocytes were often swollen with only a few short gliofilaments or with numerous gliofilaments filling the cytoplasm (Fig. 8). In their cytoplasm, lipofuscin deposits were located in the adjacent gliofilaments (Fig. 8). In capillaries, abundant collagen fibers were frequently found in the pericyte position and small clusters in different locations of the basement membrane (Fig. 9).

The analysis of the nucleotide sequence of the MAPT gene revealed an intron 10+3-splice site mutation (IVS10+3G $>$ A, g.123806G $>$ A) in both affected siblings. The analysis of diplotypes associated with mutation in the male proband and his sister showed that the IVS10+3G>A mutation was in the haplotype $\mathrm{H} 1 \mathrm{~s}$ background. The MAPT diplotype of the male proband was $\mathrm{H} 1 \mathrm{~s} / \mathrm{H} 1 \mathrm{~b}$, and that of his sister was H1s/H1j (Table I).

\section{Discussion}

We present a comprehensive analysis of members of the first Italian-Polish family with genetically confirmed FTLD with the IVS10+3G>A MAPT mutation. The mutation was previously reported as pathologic in another European population $[19,26,28]$ and was absent in 138 patients with FTLD in the Polish population (data not published). The analysis of the MAPT gene in the two described cases showed 

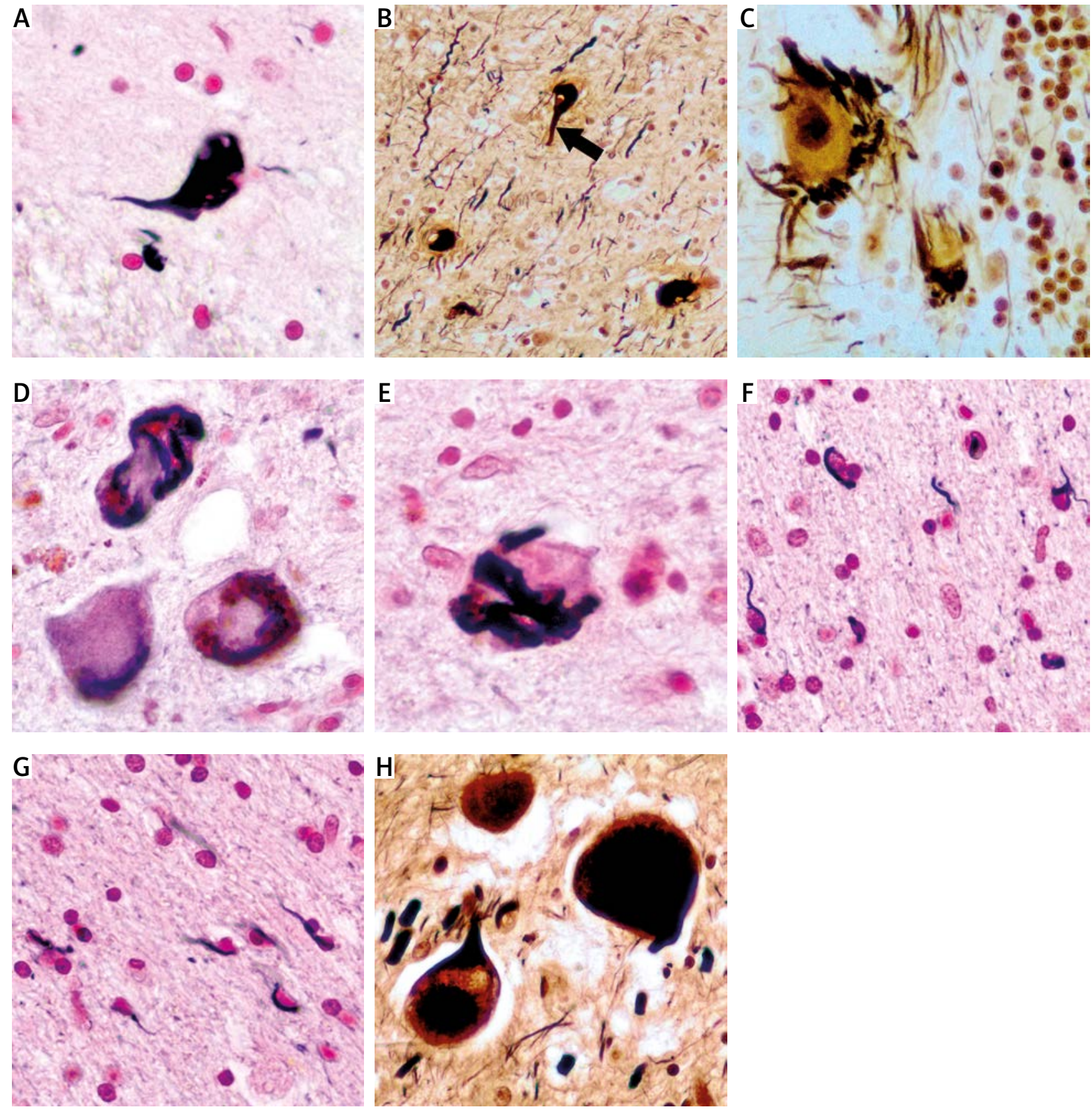

Fig. 4. Frontotemporal lobar degeneration (FTLD) with MAPT mutation. Silver techniques. A) Proband II.2. Pons. Neurofibrillary tangle (NFT). Gallyash. × 20. B) Case II.2. Temporal lobe, case II.2. Fibrillary material surrounds the nucleus and extends into the axon (arrow). Numerous neuropil threads. Yamamoto $\times 20$. C) Case II.2. Purkinje cell. Nucleus surrounded by densely packed neurofibers. Yamammoto. $\times$ 40. D) Case II.1. MesencephaIon. Intracytoplasmic argyrophilic depots. Gallyas. × 40. E) Case II.1. Pons. Argyrophilic deposits. Gallyas. $\times 40$. F) Case II.2. Coiled bodies in white matter of frontal lobe. Gallyas. $\times 40$. G) Case II.1. Coiled bodies in white matter of temporal bodies. Gallyas. $\times$ 40. H) Case II.2. Ballooned neurons in the pons. Yamammoto. $\times 40$. 

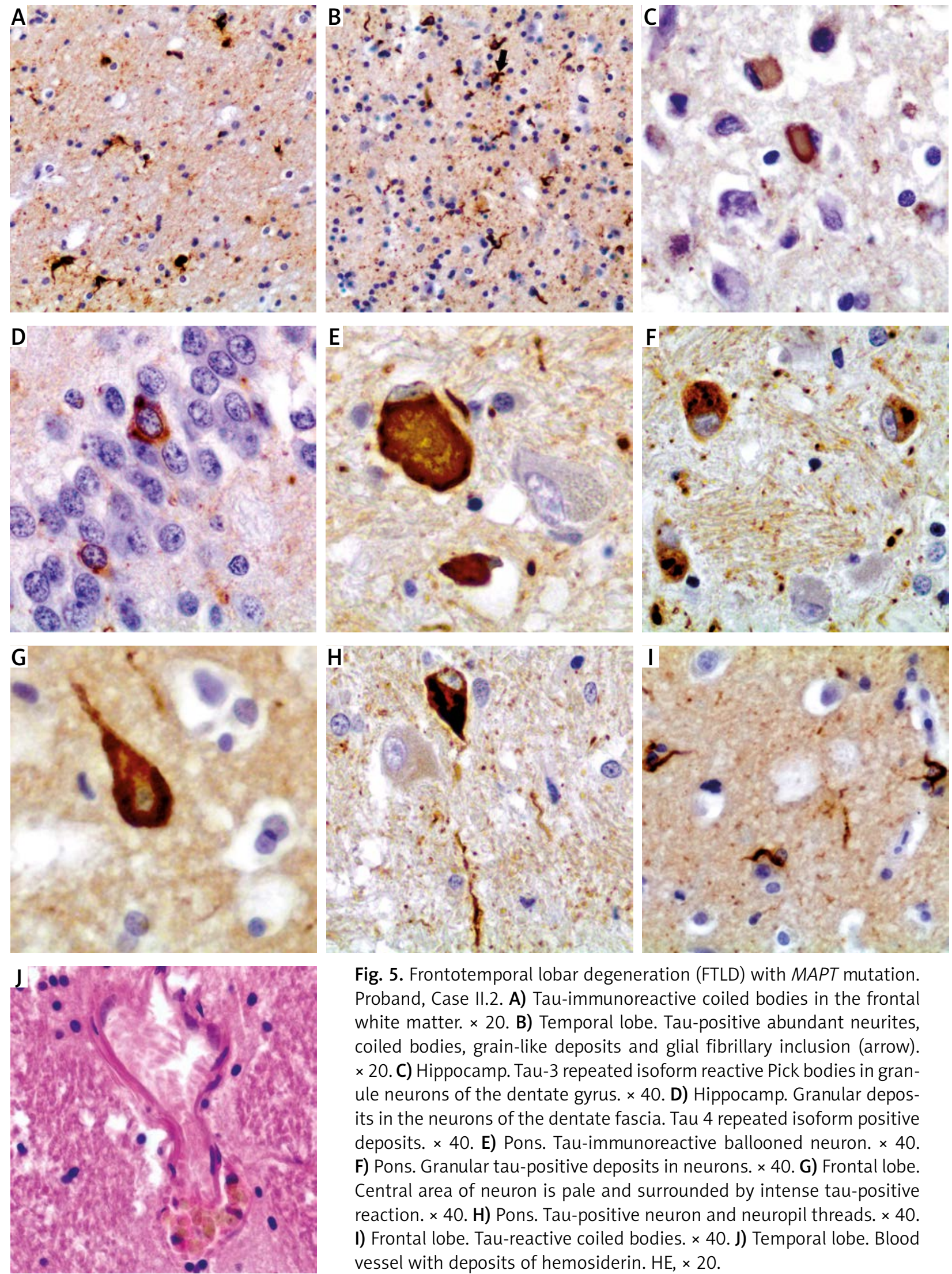

Fig. 5. Frontotemporal lobar degeneration (FTLD) with MAPT mutation. Proband, Case II.2. A) Tau-immunoreactive coiled bodies in the frontal white matter. $\times$ 20. B) Temporal lobe. Tau-positive abundant neurites, coiled bodies, grain-like deposits and glial fibrillary inclusion (arrow). $\times 20$. C) Hippocamp. Tau-3 repeated isoform reactive Pick bodies in granule neurons of the dentate gyrus. × 40. D) Hippocamp. Granular deposits in the neurons of the dentate fascia. Tau 4 repeated isoform positive deposits. $\times$ 40. E) Pons. Tau-immunoreactive ballooned neuron. $\times 40$. F) Pons. Granular tau-positive deposits in neurons. $\times 40$. G) Frontal lobe. Central area of neuron is pale and surrounded by intense tau-positive reaction. $\times 40 . \mathrm{H}$ ) Pons. Tau-positive neuron and neuropil threads. $\times 40$. I) Frontal lobe. Tau-reactive coiled bodies. $\times 40$. J) Temporal lobe. Blood vessel with deposits of hemosiderin. HE, $\times 20$. 

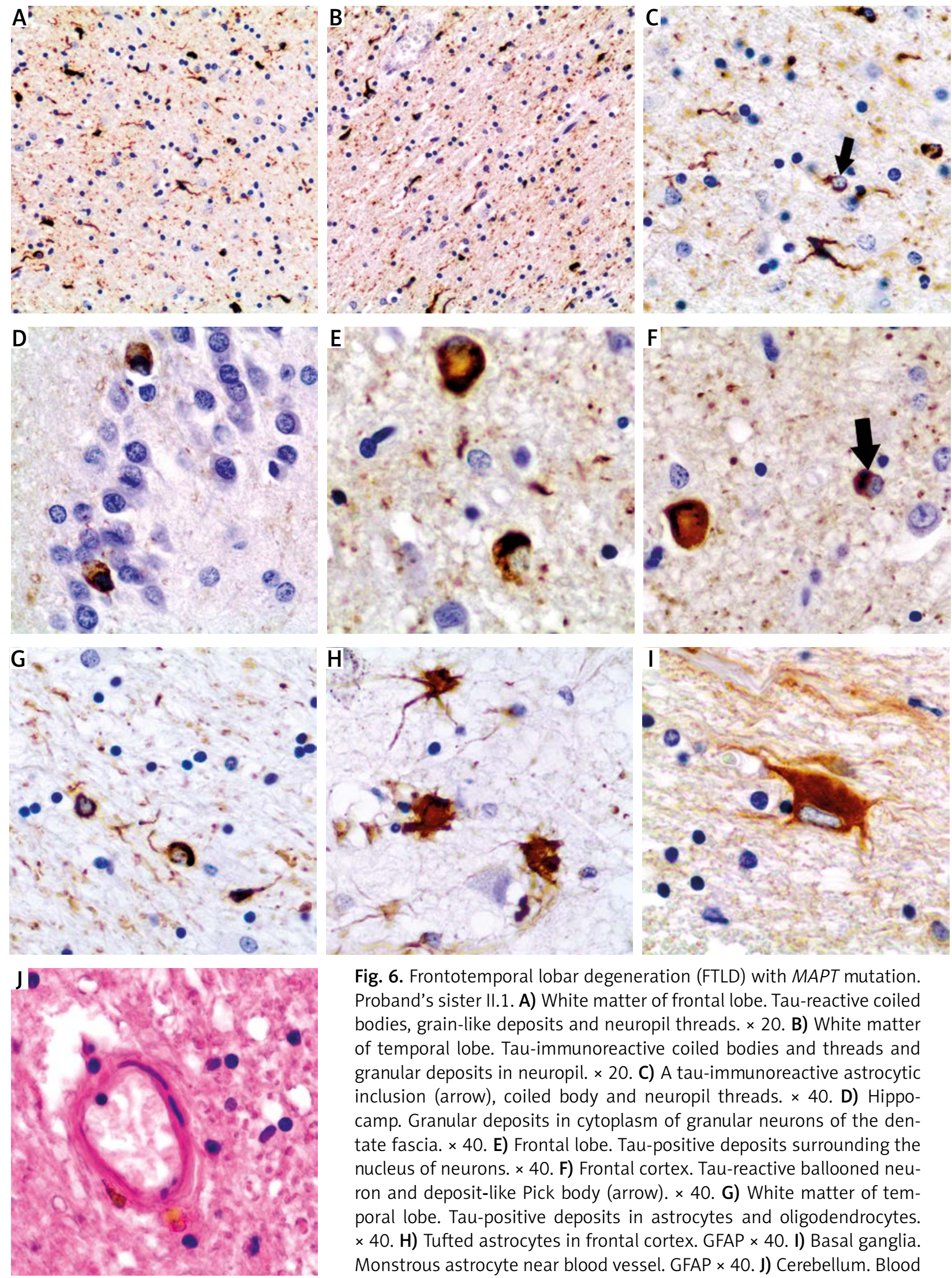

Fig. 6. Frontotemporal lobar degeneration (FTLD) with MAPT mutation. Proband's sister II.1. A) White matter of frontal lobe. Tau-reactive coiled bodies, grain-like deposits and neuropil threads. $\times 20$. B) White matter of temporal lobe. Tau-immunoreactive coiled bodies and threads and granular deposits in neuropil. $\times 20$. C) A tau-immunoreactive astrocytic inclusion (arrow), coiled body and neuropil threads. $\times$ 40. D) Hippocamp. Granular deposits in cytoplasm of granular neurons of the dentate fascia. $\times$ 40. E) Frontal lobe. Tau-positive deposits surrounding the nucleus of neurons. $\times 40$. F) Frontal cortex. Tau-reactive ballooned neuron and deposit-like Pick body (arrow). $\times 40$. G) White matter of temporal lobe. Tau-positive deposits in astrocytes and oligodendrocytes. $\times 40 . \mathrm{H})$ Tufted astrocytes in frontal cortex. GFAP $\times$ 40. I) Basal ganglia. Monstrous astrocyte near blood vessel. GFAP $\times$ 40. J) Cerebellum. Blood vessel with deposits of hemosiderin. $\mathrm{HE} \times 40$. 


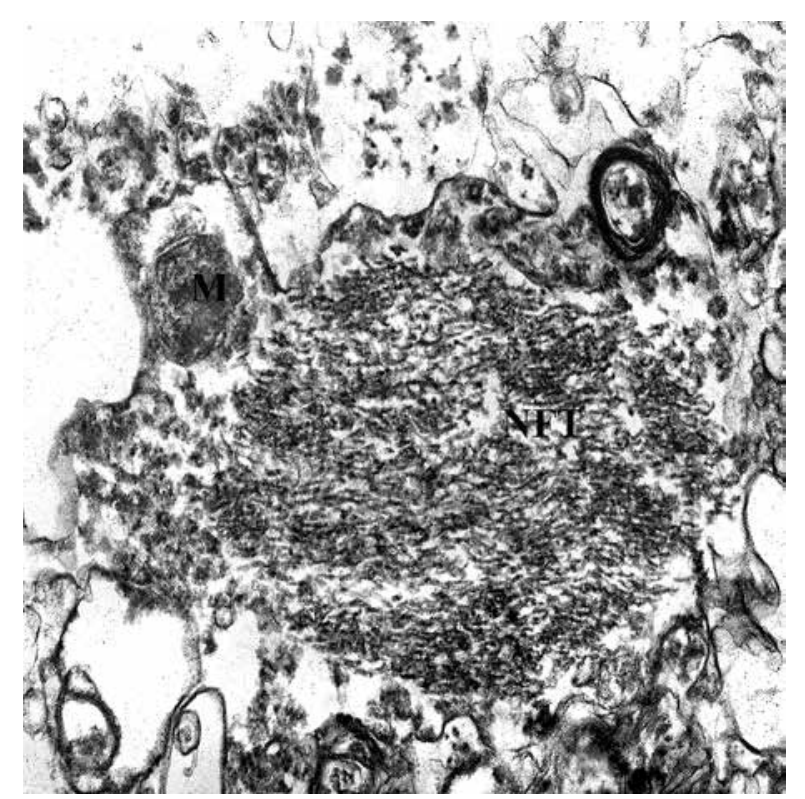

Fig. 7. Case II.1. Nerve cell cytoplasm with tightly aggregated filaments of neurofibrillary tangles (NFT). M - mitochondrium. Org. mag. × 12000 .

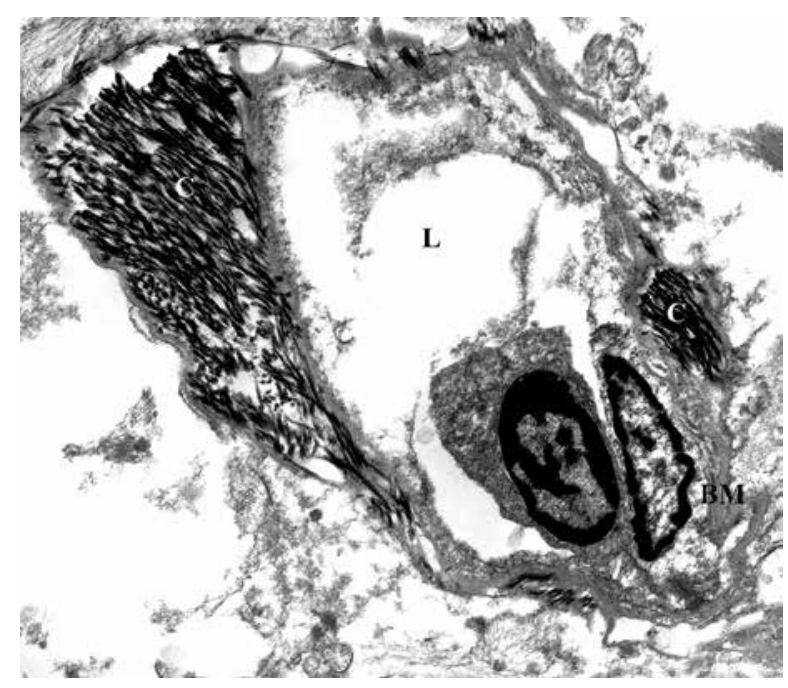

Fig. 9. Proband. Case II.2. Capillary. Collagen fibers $(C)$ in the basement membrane (BM) and in the pericyte position. $L-$ lumen. Orig. mag. $\times 4400$.

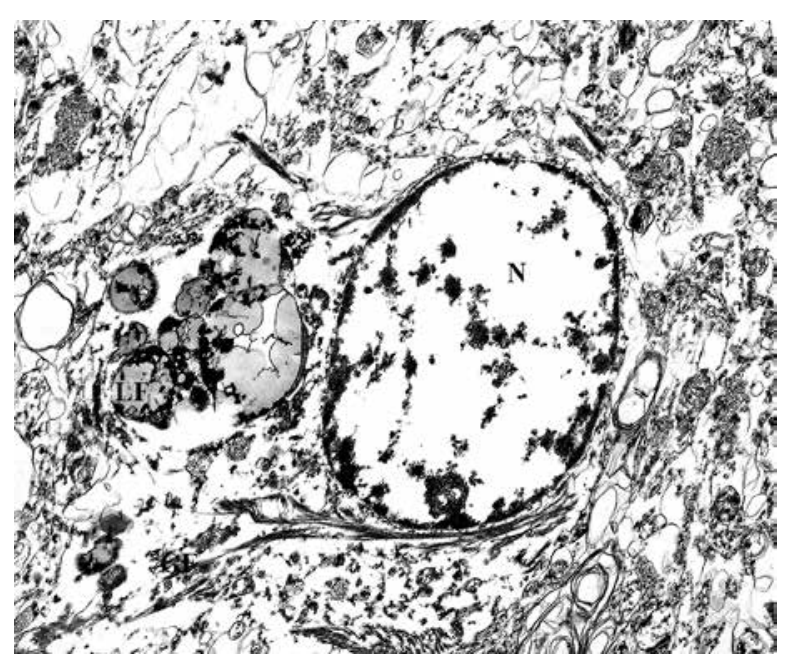

Fig. 8. Case II.1. Astrocyte with numerous bundles of gliofilaments (GF) and lipofuscin (LF) in the cytoplasm. $\mathrm{N}$ - nucleus. Orig. mag. $\times 4400$.

that the IVS10+3G>A mutation was in the haplotype $\mathrm{H} 1 \mathrm{~s}$ background. There were differences in the MAPT diplotypes. The male proband's diplotype was $\mathrm{H} 1 \mathrm{~s} / \mathrm{H} 1 \mathrm{~b}$, while his sister's was $\mathrm{H} 1 \mathrm{~s} / \mathrm{H} 1 \mathrm{j}$. It is possible that these variations affected the differences in the clinical course of the disease and in its neuropathological picture [28]. The male proband died one year after the onset of symptoms of dementia and 9 years after implantation of a cardiac pacemaker. The sister of the proband experienced brain hemorrhagic stroke 2 years after disease onset and died 9 years after the first symptoms of dementia. The mutation in the microtubule protein tau (MAPT) gene locus into haplotype $\mathrm{H} 1$ affected tau microtubule assembly and tau mRNA splicing. In addition, the increased inclusion of exon 10 in transcripts show an imbalance in the $3 R$ and $4 R$ tau isoforms $[2,9,15]$.

The ratio of these two isoforms in normal conditions is generally equal $(1: 1)$, but it varies depending on the type of mutation [24]. Corticobasal degeneration (CBD) is characterized by increased $4 \mathrm{R}$ tau,

Table I. Mutation analysis of MAPT gene - ideogram

\begin{tabular}{|lccccccc|}
\hline & Rs1467967 & Rs242557 & Rs3785883 & Rs2471738 & Del-in9 & IVS10+3 & Rs7521 \\
\hline Proband & G/G & G/G & G/G & C/C & H1/H1 & G/A & G/A \\
\hline Shared alleles & G & G & G & C & H1 & A & G \\
\hline Sister & G/G & G/G & G/G & C/C & H1/H1 & G/A & G/G \\
\hline
\end{tabular}


whereas frontotemporal lobar degeneration with Pick bodies shares an overabundance of $3 R$ tau (Fig. 1). FTLD with MAPT mutation is a biochemically heterogeneous disease associated with $3 R$ and $4 R$ tau deposits in various proportions, influencing the type of neuropathological changes. The main cellular function of tau protein is to assemble and stabilize microtubules and neural integrity. The aggregation of microtubules and creation of NFTs may be regarded as "toxic intensification" of their function in neurons $[21,23]$. These disorders may start aging processes leading finally to apoptosis. The clinical course of FTLD with MAPT mutation is also heterogeneous, because of the tau protein function in the cells outside the nervous system $[1,8,16]$. Ultrastructurally, in both cases, we observed neurofibrillary pathology and deposits of collagen in the vessel walls of the male proband's brain [10]. Šerý et al. [24] suggest that vascular pathology influences pathological processes in Alzheimer's disease [14]. Our report suggests that FTLD with MAPT mutation affects mainly the CNS, and neuropathological changes depend on the variant of the mutation. In the clinical course of this disease, damage of the cardiovascular system may also be observed.

\section{Disclosure}

\section{Authors report no conflict of interest.}

\section{References}

1. Birukova AA, Birukov KG, Gorshkov B, Liu F, Garcia JGN, Verin AD. MAP kinases in lung endothelial permeability induced by microtubule disaessembly. AMJ Physiol Lung Cell Mol Physiol 2005; 289: L75-L-84.

2. Caffrey TM, Wade-Martins R. Functional MAPT haplotypes: Bridging the gap between genotype and neuropathology. Neurobiol Dis 2007; 27: 1-10.

3. Cainrs NJ, Bigio EH, Mackenzie IRA, Neumann M, Lee V M-Y, Hatanpaa KJ, White III ChL, Schneider JA, Grinberg LT, Halliday G, Duyckaert Ch, Lowe JS, Holm IE, Tolnay M, Okamoto K, Yokoo H, Murayama S, Woulfe J. Munoz DG, Dickson DW, Ince PG, Trojanowski JQ, Mann DMA. Neuropathologic diagnostic and nosologic criteria for frontotemporal lobar degeneration: consensus of the Consortium for Frontotemporal Lobar Degeneration. Acta Neuropathol 2007; 114: 5-22.

4. Cainrs NJ, Neumann M, Bigio EH, Holm IE, Troost D, Hatanpaa KJ, Foong Ch, White III CHL, Schneider JA, Kretzschmar HA, Carter D, Taylor-Reinwald L, Paulsmeyer K, Strider J, Gitcho M, Goate AM, Morris JC, Mishra M, Kwong LK, Stieber A, Xu Y, Forman MS, Trojanowski JQ, Lee VM-Y, Mackenzie JRA. TDP-43 in familial and sporadic frontotemporal lobar degeneration with ubiquitin inclusions. Am J Pathol 2007; 171: 227-240.
5. de Silva R, Lashley T, Gibb G, Hanger D, Hope A, Reid A, Brandopadhyay R, Utton M, Strand C, Jowett T, Khan N, Anderton B, Wood N, Holton J, Revesz T, Lees A. Pathological inclusion bodies in tauopathies contain distinct complements of tau with three or four microtubule-binding repeat domains as demonstrated by new specific monoclonal antibodies. Neuropathol Appl Neurobiol 2003; 29: 288-302.

6. de Silva R, Lashley T, Strand C, Shiarli AM, Shi J, Tian J, Bailey KL, Davies P, Murayama S, Kretzschmar H, Neumann M, Lippa C, Halliday G, Mackenzie J, Ravid R, Dickson D, Wszolek Z, Iwatsubo T, Pickering-Brown SM, Holton J, Lees A, Revesz T, Mann DMA. An immunohistochemical study of cases of sporadic and inherited frontotemporal lobar degeneration using 3R- and 4R-specific tau monoclonal antibodies. Acta Neuropathol 2006; 111: 329-340.

7. Goedert M, Ghetti B, Spillantini MG. Frontotemporal dementia: implication for understanding Alzheimer's disease. Cold Spring Harb Perspect Med 2012; 2: a006254.

8. Ingelson M, Vanmechelen E, Lannfelt L. Microtubule-associated protein tau in human fibroblasts with the Swedish Alzheimer mutation. Neuroscience Lett 1996; 220: 9-12.

9. Iovino M, Pfisterer U, Holton JL, Lashley T, Swingler RJ, Calo L, Treacy R, Revesz T, Parmar M. Goedert M, Muqit MMK, Spillantini MG. The novel MAPT mutation K298E: mechanisms of mutant tau toxicity, brain pathology and tau expression in induced fibroblast-derived neurons. Acta Neuropathol 2014; 127: 283-295.

10. Kato S, Nakamura H, Otomo E. Reappraisal of neurofibrillary tangles. Immunohistochemical, ultrastructural and immunoelectron microscopical studies. Acta Neuropathol 1989; 77: 258266.

11. Komori T. Tau-positive glial inclusions in progressive supranuclear palsy, corticobasal degeneration and Pick's disease. Brain Pathol 1999; 9: 663-679.

12. Kowalska A. The genetics of dementias. Part 1: Molecular basis of frontotemporal dementia and parkinsonism linked to chromosome 17 (FTDP-17). Postepy Hig Med Dosw 2009; 63: 278286.

13. Kovacs GG, Rozemuller AJM, van Swieten JC, Gelpi E, Majtenyi K, A-Sarraj S, Troakes C, Bodi I, King A, Hortobagyi T, Esiri MM, Ansorge O, Giaccone G, Ferrer I, Arzbeger T, Bogdanovic N, Nilsson T, Leisser I, Alafuzoff I, Ironside JW, Kretzschmar H, Budka H. Neuropathology of the hippocampus in FTLD-Tau with Pick bodies: A study of the BrainNet Europe Consortium. Neuropathol Appl Neurobiol 2013; 39: 166-178.

14. Lipiński B, Pretorius E. Iron-induced fibrin formation may explain vascular pathology in Alzheimer's disease. Folia Neuropathol 2014; 52: 205.

15. Myers AJ, Pittman AM, Zhao AS, Rohrer K, Kaleem M, Marlowe L. Lees A, Leung D, McKeith IG, Perry RH, Morris ChM, TrojanowskiJQ, Clark Ch, Karlawish J, Arnold S, Forman MS, Deerlin VV, de Silva R, Hardy J. The MAPT H1c risk haplotype is associated with increased expression of tau and especially of 4 repeat containing transcripts. Neurobiol Dis 2007; 25: 561-570.

16. Nagao SI, Kumamoto T, Masuda T, Uekyama H, Toyoshima I, Tsuda T. Tau expression in denervated rat muscles. Muscle Nerve 1999; 22: 61-70. 
17. Narożańska E, Jasińska-Myga B, Sitek EJ, Robowski P, Brockhuis B, Lass P, Dubaniewicz M, Wieczorek D, Baker M, Rademakers R, Wszołek ZK, Stawek J. Frontotemporal dementia and parkinsonism linked to chromosome 17 - the first Polish family. Eur J Neurol 2011; 18: 535-537.

18. Neary D, Snowden JS, Mann DM. Classification and description of frontotemporal dementias. Ann NY Acad Sci 2000; 920: 46-51.

19. Neumann M, Mittelbronn M, Simon P, Vanmassenhove B, de Silva R, Lees A, Klapp J, Meyermann R, Kretzschmar HA. A new family with frontotemporal dementia with intronic $10+3$ splice site mutation in the tau gene: neuropathology and molecular effects. Neuropathol Appl Neurobiol 2005; 31: 362-373.

20. Onyike CU, Diehl-Schmid J. The epidemiology of frontotemporal dementia. Int Rev Psychiatry 2013; 25: 130-137.

21. Pickering-Brown SM, Baker M, Nonaka T, Ikeda K, Sharma S, Mackenzie J, Simpson SA, Moore JW, Snowden JS, de Silva R, Revesz T, Hasegawa M, Hutton M, Mann DMA. Frontotemporal dementia with Pick-type histology associated with Q336R mutation in the tau gene. Brain 2004; 127: 1415-1426.

22. Pittman AM, Myers AJ, Abou-Sleiman P, Fung HC, Kaeleem M, Marlowe L, Duckworth J, Leung D, Williams D, Kilford L, Thomas N, Morris CM, Dickson D, Wood NW, Hardy J, Lees AJ, de Silva R. Linkage disequilibrium fine mapping and haplotype associatrion analysis of the tau gene in progressive supranuclear palsy and corticobasal degeneration. J Med Genet 2005; 42: 837-846.

23. Rossi G, Bastone A, Piccoli E, Mazzoleni G, Morbin M, Uggetti A, Giaccone G, Sperber S, Beeg M, Salmona M, Tagliavini F. New mutations in MAPT gene causing frontotemporal lobar degeneration: biochemical and structural characterization. Neurobiol Aging 2012; 33: 834.el-6.

24. Šerý O, Popová J, Mišek I, Pešák L, Janout V. Molecular mechanisms of neuropathological changes in Alzheimer's disease: a review. Folia Neuropathol 2013; 51: 1-9.

25. See TM, LaMarre AK, Lee SE, Miller BL. Genetic causes of frontotemporal degeneration. J Geriatr Psych Neurol 2010; 23: 260 268.

26. Spillantini MG, Murrell JR, Goedert M, Farlow MR, Klug A, Ghetti B. Mutation in the tau gene in familial multiple system taupathy with presenile dementia. Proc Natl Acad Sci U S A 1998; 95: 7737-7774.

27. Spina S, Farlow MR, Unverzagt FW, Kareken DA, Murrell JR, Fraser G, Epperson F, Crowther A, Spillantini MG, Goedert M, Ghetti B. The tuopathy associated with mutation +3 in intron 10 of Tau: characterization of the MSTD family. Brain 2008; 131: 72-89.

28. Tolnay M, Spillantini MG, Rizzini C, Eccles D, Lowe J, Ellison D. A new case of frontotemporal dementia and parkinsonism resulting from an intron $10+3$-splice site mutation in the tau gene: clinical and pathological features. Neuropathol Appl Neurobiol 2000; 2: 368-378. 